Research, Society and Development, v. 9, n. 10, e1569108162, 2020

(CC BY 4.0) | ISSN 2525-3409 | DOI: http://dx.doi.org/10.33448/rsd-v9i10.8162

\title{
A inclusão escolar na percepção do estudante universitário com deficiência física
}

School inclusion in the perception of university students with physical disabilities

Inclusión escolar en la percepción de universitarios con discapacidad física

Recebido: 03/09/2020 | Revisado: 12/09/2020 |Aceito: 19/09/2020 | Publicado: 24/09/2020

\author{
Neide Maria Fernandes Rodrigues de Sousa \\ ORCID: https://orcid.org/0000-0002-9129-0319 \\ Universidade Federal do Pará, Brasil \\ E-mail: nmfrs@ufpa.br \\ Ivany Pinto Nascimento \\ ORCID: https://orcid.org/0000-0002-2455-3676 \\ Universidade Federal do Pará, Brasil \\ E-mail: ivany.pinto@gmail.com
}

\section{Resumo}

O estudo teve como objetivo compreender a percepção do estudante universitário com deficiência física (DF) sobre a inclusão escolar. Participaram da pesquisa quatro alunos com DF, usuários de cadeira de rodas que frequentavam os cursos de ensino superior de uma universidade pública. O levantamento foi realizado através da entrevista e formulário. No tratamento dos dados foi utilizada a análise de conteúdo, sendo, estruturada em três categorias: as relações afetivas (entre professor/estudante com DF e estudante não deficiente/estudante com DF); as atividades escolares e a prática docente e as dificuldades de acesso físico. Nos resultados, os participantes revelaram afeto positivo na relação professoraluno; exceto uma participante que indicou maior prevalência de relações negativas com professores; na relação entre estudante deficiente- não deficiente, houve maior relato de frequência de interações negativas. Referente às atividades escolares e a prática docente os participantes apresentaram dificuldades nas habilidades de coordenação motora fina; três deles citaram que houve na prática docente, flexibilização/diferenciação na metodologia e na avaliação; uma participante relatou a pouca diversificação didática e avaliativa dos professores. Na categoria dificuldades de acesso físico, para os participantes a acessibilidade era em sua maioria inexistente e/ou precária. Conclui-se que é preciso refletir sobre a política educacional inclusiva e as práticas nas escolas, trabalhar a conscientização dos direitos da 
pessoa com deficiência e as possibilidades de práticas inclusivas exitosas para os alunos com DF na educação básica, com vista ao sucesso na aprendizagem, a participação social e ao empoderamento.

Palavras-chave: Deficiência física; Inclusão escolar; Prática docente e aprendizagem; Relações interpessoais; Acessibilidade.

\begin{abstract}
The study aimed to understand the perception of university students with physical disabilities (PD) about school inclusion. Four students PD, wheelchair users who attended higher education courses at a public university participated in the research. The survey was conducted through the interview and form. In the treatment of data, content analysis was used, being structured in three categories: affective relationships (between teacher / student with DF, and non-disabled student / student with PD); school activities and teaching practice; and physical access difficulties. In the results, the participants showed positive affection in the teacher-student relationship; except one participant who indicated a higher prevalence of negative relationships with teachers; in the relationship between disabled and non-disabled students, there was a greater report of the frequency of negative interactions. Regarding school activities and teaching practice, the participants had difficulties in fine motor skills; three of them mentioned that there was in the teaching practice, flexibility / differentiation in the methodology and in the evaluation; one participant reported the teachers' little didactic and evaluative diversification. In the category physical access difficulties, for the participants, accessibility was mostly non-existent and / or precarious. We conclude that it is necessary to reflect on inclusive educational policy and practices in schools, work to raise awareness of the rights of people with disabilities and the possibilities of successful inclusive practices for students with PD in basic education, with a view to successful learning, social participation and empowerment.
\end{abstract}

Keywords: Physical disability; School inclusion; Teaching and learning practice; Interpersonal relationships; Accessibility.

\title{
Resumen
}

El estudio tuvo como objetivo comprender la percepción de los estudiantes universitarios con discapacidad física (DF) sobre la inclusión escolar. En la investigación participaron cuatro estudiantes con DF, usuarios de silla de ruedas que asistieron a cursos de educación superior en una universidad pública. La encuesta se realizó a través de la entrevista y el formulario. En 
el tratamiento de los datos se utilizó el análisis de contenido, estando estructurado en tres categorías: relaciones afectivas (entre docente / alumno con DF, y alumno / alumno no discapacitado con DF); actividades escolares y práctica docente; y dificultades de acceso físico. En los resultados, los participantes mostraron un afecto positivo en la relación maestroalumno; excepto un participante que indicó una mayor prevalencia de relaciones negativas con los profesores; en la relación entre estudiantes discapacitados y no discapacitados, hubo un mayor reporte de la frecuencia de interacciones negativas. En cuanto a las actividades escolares y la práctica docente, los participantes presentaron dificultades en la motricidad fina; tres de ellos mencionaron que había en la práctica docente, flexibilidad / diferenciación en la metodología y en la evaluación; un participante informó sobre la escasa diversificación didáctica y evaluativa de los profesores. En la categoría de dificultades de acceso físico, para los participantes, la accesibilidad fue en su mayoría inexistente y / o precaria. Concluimos que es necesario reflexionar sobre las políticas y prácticas educativas inclusivas en las escuelas, trabajar para concienciar sobre los derechos de las personas con discapacidad y las posibilidades de prácticas inclusivas exitosas para los estudiantes con $\mathrm{CE}$ en la educación básica, con miras a un aprendizaje exitoso, participación social y empoderamiento.

Palabras clave: Discapacidad física; Inclusión escolar; Práctica de enseñanza y aprendizaje; Relaciones interpersonales; Accesibilidad.

\section{Introdução}

$\mathrm{Na}$ atualidade a pessoa com deficiência física tem o direito ao acesso, a participação e a aprendizagem escolar preconizado por um conjunto de diretrizes legais e políticas da educação especial inclusiva; apesar desses dispositivos oficiais, o cotidiano nas escolas vem indicar que a inclusão escolar é um grande desafio.

A inclusão educacional é conceituada como uma ação política, cultural, social e pedagógica, fundamentada na concepção de direitos humanos e em valores como igualdade, equidade e democracia; tem como diretriz o direito de todos os alunos estarem juntos, em uma participação e aprendizagem coletiva, sem qualquer tipo de discriminação negativa com vista a uma educação de qualidade (PNEEI, 2008).

Alguns aportes legais e políticos normatizam e indicam diretrizes para a educação especial inclusiva direcionado ao público alvo da educação especial (PAEE) como a Política Nacional de Educação Especial na perspectiva da Educação Inclusiva de 2008, a Base Nacional Comum Curricular de 2017 e o Estatuto da Pessoa com Deficiência de 2015. 
A partir de um modelo educacional inclusivo, a educação especial disponibiliza um conjunto de recomendações às instituições escolares, e.g.: transformações no projeto pedagógico (PPC) e consequentemente no currículo escolar; construções de novas práticas pedagógicas associadas a mudanças nas metodologias, recursos e avaliação; formação de professores; acessibilidade física ou arquitetônica; eliminação de barreiras atitudinais e de comunicação na ideia de garantir a aprendizagem, a participação e o sucesso na escolarização dos estudantes (Glat, 2011; Sousa, Nascimento, 2018).

As barreiras pedagógicas (como a falta de recursos complementares e suplementares e de metodologias específicas) dificultam a aprendizagem dos estudantes públicoalvo da educação especial (PAEE) e o acesso ao currículo (Pletsch, 2014).

A acessibilidade é uma dimensão fundamental na inclusão do estudante com DF, visto que assegura o direito de participação em igualdade de condições. Documentos legais como o Estatuto da Pessoa com Deficiência (Lei n. 13.146, 2015) e o Decreto n. 5.296 (2004) vem conceituar e determinar normativas de acessibilidade. A acessibilidade caracteriza-se como possibilidade e condição de alcance para o uso, com segurança e autonomia, dos espaços, mobiliários, equipamentos urbanos, edificações, transportes, informação e comunicação, inclusive seus sistemas e tecnologias pela pessoa com deficiência ou com mobilidade reduzida. Os estabelecimentos de ensino de qualquer nível, etapa ou modalidade, propiciarão condições de acesso e utilização de todos os seus espaços ou compartimentos para pessoas com deficiência ou com mobilidade reduzida.

Segundo Baú (2015) a acessibilidade arquitetônica está relacionada ao direito de todos ao acesso e a participação para a utilização efetiva dos espaços, prevê a inclusão e o exercício da cidadania para que a pessoa com deficiência possa usufruir em condições de igualdade das diversas instâncias sociais, tais como: educação, saúde, lazer, etc.

A despeito de documentos oficiais e das diretrizes de um modelo inclusivo direcionado para o atendimento educacional ao PAEE, a realidade desvela que a inclusão de estudantes com deficiência/deficiência física na educação básica revela-se como um processo complexo marcado por retrocessos, algumas conquistas e grandes desafios. De forma geral na educação escolar do PAEE as práticas excludentes continuam a acontecer no dia a dia das escolas; se faz necessário discutir políticas que garantam de fato o direito a uma educação inclusiva, bem como avançar em práticas inclusivas exitosas (Glat, 2011; Pletsch, 2011, 2014).

Dentre o grupo PAEE atendido nas escolas, temos a pessoa com deficiência física (DF), que pode ser conceituada a partir de uma perspectiva biológica e social. O modelo 
social define a DF como uma categoria cultural significativa que tem como características uma perda motora e práticas culturais que discriminam o indivíduo em função dessa diferença física. No modelo biológica as deficiências físicas são caracterizadas por um comprometimento do aparelho locomotor que compreende o sistema osteoarticular, o sistema muscular e nervoso e afetam os padrões e movimentos de estabilização (Couser, 2005; Diehl, 2006).

A inclusão de estudante com DF nas escolas não envolve apenas uma dimensão legal, mais políticas e práticas exitosas, que leve o estudante a apresentar saltos qualitativos na aprendizagem. No aspecto organizacional da escola um conjunto de ações deve ser considerado: modificações no PPC e currículo (nas práticas, metodologias e formas de avaliação específicas), uso de Tecnologias Assistivas, além da acessibilidade arquitetônica.

A partir desse cenário é que situamos essa pesquisa; assim na intenção de colaborar com as discussões na área e permitir reflexões significativas sobre a escolarização de estudantes com DF em uma perspectiva inclusiva; esta pesquisa teve o objetivo de compreender como ocorreu a inclusão escolar no ensino fundamental e médio de universitários com deficiência física (DF).

\section{Metodologia}

Neste estudo optou-se por uma abordagem qualitativa, do tipo pesquisa descritiva interpretativa, o que possibilitou analisar a percepção dos universitários com deficiência física (DF) sobre a inclusão escolar no ensino médio e fundamental. Segundo Santos Filho \& Gamboa (2009) uma pesquisa de natureza qualitativa tem o caráter de buscar a compreensão de determinado fenômeno social, no qual o pesquisador tenta interpretar os significados que os atores sociais dão as suas situações, desveladas nas ideias, nos sentimentos, nos afetos, nos valores, nas crenças, entre outros. Para Gonçalves (2005) na pesquisa descritiva há preocupação de se verificar as características de determinado fenômeno social, ocorrendo a descrição, o registro e a análise do objeto de pesquisa.

O levantamento foi realizado em um campus de uma universidade pública com quatro estudantes universitários com DF de diferentes cursos. Apesar do tamanho da amostra ser pequena, esta corresponde ao total de estudantes com DF, usuário de cadeiras de rodas do campus em questão.

Os participantes tinham deficiência física (DF) com paraplegia congênita e eram usuários de cadeira de rodas; apresentavam a idade entre 19 a 35 anos, sendo uma do sexo 
feminino e três do sexo masculino; todos eram solteiros. A renda mensal familiar variava de 4 a 2 salários mínimos, sendo que dois participantes tinham benefício social e dois tinham trabalho remunerado. Para garantir a confidencialidade dos participantes do estudo anonimizamos os nomes; desse modo, denominamos os participantes de Carlos, Eurico, Ivo e Diana. Na pesquisa foram utilizados como critérios de inclusão: ser estudante com DF com comprometimento nos membros inferiores, usuário de cadeira de rodas e sem possibilidade de andar; além de estar matriculado na instituição e ter frequência (regular) nas aulas. As informações sobre o perfil estão no Quadro 1.

Quadro 1. Perfil sócio econômico.

\begin{tabular}{|l|l|l|l|l|}
\hline Participantes & Carlos & Eurico & Ivo & Diana \\
\hline Idade & 19 & 23 & 24 & 35 \\
\hline Sexo & Masculino & Masculino & Masculino & Feminino \\
\hline Cor & $\mathrm{P}$ & $\mathrm{P}$ & $\mathrm{P}$ & $\mathrm{P}$ \\
\hline Estado civil & $\mathrm{S}$ & $\mathrm{S}$ & $\mathrm{C}$ & $\mathrm{S}$ \\
\hline Filhos & 0 & 0 & 0 & 0 \\
\hline Religião & Católica & Católica & Católica & Católica \\
\hline Escolaridade & $\begin{array}{l}\text { Superior } \\
\text { incompleto }\end{array}$ & $\begin{array}{l}\text { Superior } \\
\text { incompleto }\end{array}$ & $\begin{array}{l}\text { Superior } \\
\text { incompleto }\end{array}$ & $\begin{array}{l}\text { Superior } \\
\text { incompleto }\end{array}$ \\
\hline Emprego/Trabalho & Não & Não & Sim & Não \\
\hline Residência própria & Sim & Sim & Sim & Sim \\
\hline Benefício social & Sim & Não & Sim & Sim \\
\hline $\begin{array}{l}\text { Renda mensal } \\
\text { familiar }\end{array}$ & $\begin{array}{l}\text { 2salários } \\
\text { mínimo }\end{array}$ & $\begin{array}{l}4 \text { salários } \\
\text { mínimos }\end{array}$ & $\begin{array}{l}3 \text { salários } \\
\text { mínimos }\end{array}$ & $\begin{array}{l}\text { 2 salários } \\
\text { mínimos }\end{array}$ \\
\hline
\end{tabular}

Fonte: Próprios autores.

Os instrumentos de levantamento adotados foram o formulário e a entrevista. O formulário foi usado para caracterização do perfil socioeconômico dos participantes; as questões estavam direcionadas para as informações sobre idade, sexo, etnia, religião, estado civil, configuração familiar, renda familiar, escolaridade do sujeito, tipo de deficiência, acessos à saúde, ao lazer, ao transporte coletivo e ao benefício social. Na entrevista utilizou-se um roteiro com questões sobre as relações sociais na escola, as atividades pedagógicas 
(prática docente, ensino-aprendizagem, recursos e formas de avaliação escolar), acessibilidade física ou arquitetônica, barreiras atitudinais. Foram realizadas duas entrevistas com duração aproximada de duas horas para cada sujeito, em dias alternados; elas foram gravadas com a concordância dos participantes.

$\mathrm{O}$ procedimento foi organizado em duas fases. $\mathrm{Na} 1^{\mathrm{a}}$ fase foi realizado $\mathrm{o}$ reconhecimento do universo populacional e a localização dos alunos usuários de cadeira de rodas. $\mathrm{Na} 2^{\mathrm{a}}$ fase foi feito contato com os participantes, solicitada autorização para pesquisa e aplicado o formulário e as entrevistas; foi solicitada também, autorização dos participantes através do preenchimento do Termo de Consentimento Livre e Esclarecido.

\section{Resultados e Discussão}

O tratamento e análise dos dados foram realizados para possibilitar a compreensão da percepção dos universitários com DF sobre aspectos da inclusão no ensino fundamental e médio. Nesta visão articulam-se elementos afetivos, mentais e sociais com a integração das práticas, das relações sociais e do contexto socioeconômico.

Nos depoimentos os participantes desvelaram os significados, expressos em ideias, sentimentos, afetos, emoções e valores, ações e imagens, resgatando cenas de situações vivenciadas, o que permitiu responder ao objetivo da pesquisa. Assim, a análise dos depoimentos permitiu agrupar os dados em categorias temáticas, conforme indicado na Figura 1.

Figura 1. Categorias e subcategorias temáticas da pesquisa.

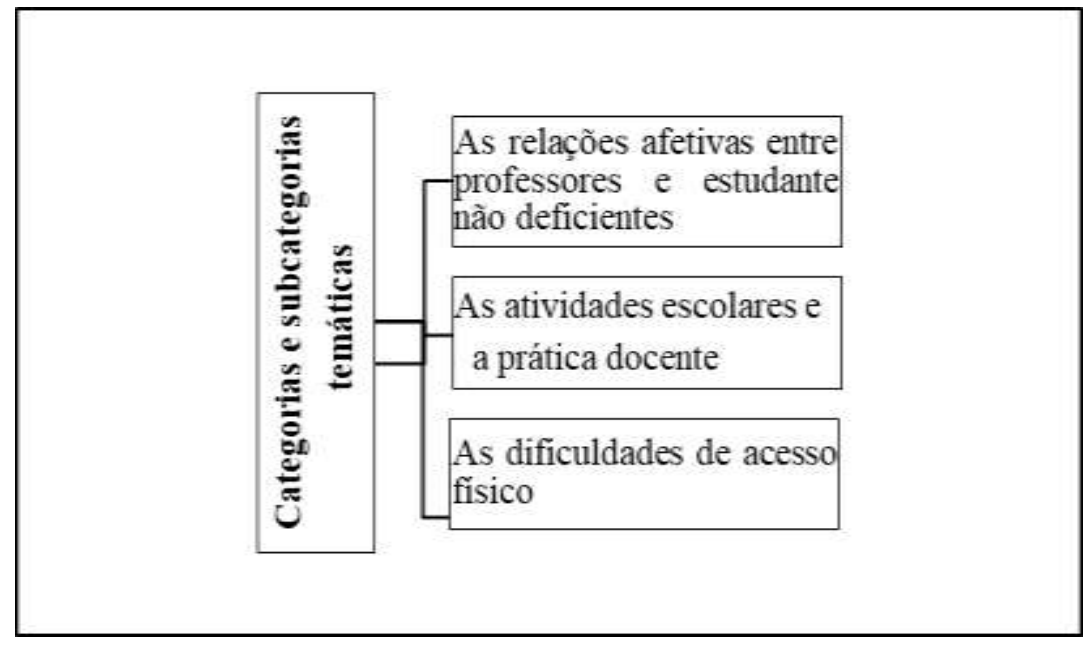

Fonte: Próprios autores 
As três categorias temáticas: 1. As relações afetivas- entre professores e entre estudantes não deficientes, 2. As atividades escolares e a prática docente, e 3. As dificuldades de acesso físico possibilitaram perceber aspectos da inclusão escolar dos universitários com DF. Deste modo, se buscou interpretar o significado dado as situações vividas construídas no cotidiano escolar: as relações com os pares (estudantes) e professores, as atitudes e as dificuldades de interações, o acolhimento de alguns professores e a ausência de outros, os preconceitos e agressões sofridos; as atividades escolares e os processos de ensinoaprendizagem, os sentimentos vivenciados, as dificuldades, os valores e as ideias produzidas; e a pouca acessibilidade física nos espaços escolares promovendo transtornos e sentimento de mal-estar.

\section{As relações afetivas entre professores e estudante não deficientes}

Esta categoria agrega depoimentos dos estudantes com DF sobre os tipos de relações vivenciadas com os professores e com estudantes não deficientes. Estes relatos foram apoiados tanto no aspecto sócio-afetivo, quanto no cognitivo, associando sentidos e lembranças de atitudes, ações e vocalizações, da figura do professor e dos estudantes não deficientes.

Os estudantes expressaram o significado dado à relação professor-aluno no qual o afeto (positivo e negativo), a compreensão, a linguagem e o pensamento estavam engendrados. Carlos, Eurico e Ivo indicaram em suas narrativas situações de relação positiva ou afetividade prazerosa com professores no ensino fundamental e médio. Para os participantes os sentidos à figura e atitudes dos professores foram de acolhimento, paciência, compreensão, justiça, generosidade, atendimento as necessidades da deficiência e defesa contra o bullying.

Diana em seus relatos sobre a relação professor-aluno expressou tanto episódios de relações positivas, quanto negativas, com maior destaque para depoimentos de afetividade negativa; nas falas sobre o relacionamento estavam presentes principalmente atitudes de preconceito, indiferença e agressividade das professoras. Essas atitudes ajudaram a produzir uma autopercepção negativa. A participante também narrou situações de atitudes acolhedoras e compreensivas de algumas professoras, segundo a mesma, foram poucos anos de convivência positiva e esse tipo de convivência ajudou a melhorar sua autoestima e a percepção de si. 
Research, Society and Development, v. 9, n. 10, e1569108162, 2020

(CC BY 4.0) | ISSN 2525-3409 | DOI: http://dx.doi.org/10.33448/rsd-v9i10.8162

Além dos significados, os participantes trouxeram imagens, lembranças que guardam nas memórias. Carlos, Eurico, e Ivo recordaram imagens da ação docente: cenas da professora defendendo contra alunos que os tratavam com agressividade, episódios de respeito a todos os alunos na sala de aula, sem fazer diferença entre estudantes; momentos de ajuda aos participantes em decorrência da dificuldade motora nos membros superiores, inerente à deficiência física. Outra cena lembrada pelos estudantes foi a flexibilização na avaliação, onde em muitos momentos eles faziam prova oral e não era exigido o desenho geométrico nas aulas e provas de matemática.

Diana lembrou em seu relato, principalmente situações constrangedoras na relação com professores, imagens de afetividade desprazerosa. Algumas professoras comparavam-na negativamente com outros alunos e ignoravam suas dificuldades motoras e de aprendizagem. Essas ações das professoras geravam em Diana um sentimento de insegurança, de se sentir incapaz e desmotivada.

Vejamos algumas narrativas dos estudantes com DF sobre a relação professor-aluno:

[...] Sempre foram ótimos comigo. Lá os professores e colegas eram ótimos se tinha um problema, os professores tentavam resolver, como por exemplo, o atraso na impressão da prova (Eurico).

Ficava chateada quando acertava alguma coisa que ninguém acertava e a professora se admirava e dizia: "Até a Maria que tem problemas conseguiu acertar essa questão e vocês não”. Com esse comentário ela demonstrava que me achava uma pessoa incapaz de aprender [...]. Posso recordar acontecimentos marcantes para mim, como a fala de uma professora que dizia: "tu nunca sai da $4^{a}$ série, assim, não chegarás a lugar algum” [...]. (Diana).

Os dados evidenciam maior quantidade de afetividade positiva do que negativa na relação professor-aluno expressos nas temáticas: auxílio ao aluno, compreensão e respeito, o que impactou na sensação de pertencimento a escola, na autoestima do aluno e na capacidade de aprender. Uma participante expressou e retratou situações negativas na convivência com professores. Portanto, na dinâmica interacional destacaram-se: a afetividade prazerosa ou positiva com emoções, atitudes, afeto, compreensão e consciência; assim também, em menor frequência houve relatos de descaso, de indiferença e de agressividade no contato de professores com estudantes com DF. 
Miras (2004) afirma que as reações emocionais do professor e a informação afetiva que o aluno recebe do professor são importantes para compreender e regular as próprias relações. Em algumas situações os estudantes aprendem a ocultar as emoções negativas para permanecer no contexto escolar, e quando há uma alta intensidade de emoção negativa, possivelmente os estudantes se concentram mais no aspecto afetivo-emocional do que na dimensão cognitiva no ensino-aprendizagem. A autora também destaca que afeto e aprendizagem estão intrinsicamente relacionados, a forma como o professor reage emocionalmente diante do sucesso ou fracasso do aluno influencia a autoestima e a expectativa de sucesso do mesmo.

Na mesma linha de argumentação Baker (2006), ressalta a qualidade da relação professor-aluno e a influência no ensino-aprendizagem, com repercussão na adaptação escolar, na autoconfiança e na motivação dos estudantes.

Sobre a relação entre aluno com DF e alunos sem deficiência, os participantes relataram maior prevalência de interações negativas. Diana e Ivo trouxeram depoimentos da qualidade das interações com os colegas da escola; os temas mais recorrentes foram: afetividade e emoções negativas, deficiência, diferença, discriminação, preconceito, valores, agressividade física e verbal, bullying falta de respeito. Associado a esses significados os participantes relembram situações vividas, cenas em que os colegas não deficientes zombavam do corpo deficiente, apelidavam de aleijado (a), escutavam piadas sobre sua deficiência e brincavam com suas cadeiras de rodas sem autorização dos mesmos e em algumas situações eles caiam da cadeira de rodas. Essas experiências provocavam um conjunto de sentimentos e atitudes como tristeza, mal-estar, vontade de abandonar a escola, constrangimento, sensação de não se sentir pertencente ao grupo e dificuldade de se relacionar e fazer amizades. O depoimento de Ivo mostra os sentidos dados, relembrando imagens sobre a relação com os colegas da escola, interações estas marcadas pelo preconceito, agressão e falta de consciência.

Não havia muito respeito dos colegas; na $6^{a}$ serie, na aula de educação física, um aluno mexeu comigo, e falou mal minha família, ai dei uma cotovelada nele, e com a cotovelada que dei nele, ele era gordinho, ele teve falta de ar, foi nós dois para diretoria, não mexeu mais comigo. Na $8^{a}$ serie, alguns alunos bagunceiros, pegavam minha cadeira e rodavam e rodavam ou corriam com ela em linha reta. Eu ficava triste; ai, eu não quis mais estudar, depois passou. 
Research, Society and Development, v. 9, n. 10, e1569108162, 2020

(CC BY 4.0) | ISSN 2525-3409 | DOI: http://dx.doi.org/10.33448/rsd-v9i10.8162

Os relatos dos participantes sobre a relação negativa entre aluno com DF e alunos sem deficiência remete discutir a representação da pessoa com deficiência na correlação com o conceito de normalidade e preconceito.

Historicamente, a pessoa com deficiência foi compreendida segundo um modelo médico, a partir de um parâmetro de normalidade, que se fundamentou na ideia de que a deficiência era uma condição individual. A deficiência foi associada à ideia de desvio de curva média, de anormalidade, de déficit, de diferença, um mecanismo de segregação a uma parte da população.

Em contrapartida, ao modelo médico, o paradigma social surgiu na década de 60 do século passado, compreende a deficiência como uma construção social, a partir da relação do indivíduo e as condições da sociedade (históricas, materiais e políticas) que discriminam, diferenciam e excluem.

Portanto, é sugestivo pensar que os colegas da escola que agrediram e desrespeitaram os estudantes Ivo e Diana tiveram atitudes preconceituosas e discriminatórias a partir de uma visão da deficiência/diferença enquanto anormalidade e inferioridade. Essa categoria desvela a necessidade de se compreender o sentido das atitudes preconceituosas a partir da visão de deficiência e diferença.

Segundo Guareschi (1992) os critérios de "normalidade" são rotativos, sofrem alguma alternância e implica relações de poder. Esses significados são alterados conforme o contexto político, cultural e histórico da sociedade afirma que. Nessa mesma linha de argumentação, Amaral (1998) afirma que a diferença significativa (a partir de aspectos como peso, cor, cognição, opção sexual, religião, gênero, envelhecimento e deficiência entre outros) foi considerada desvio ou anormalidade. Para a autora a deficiência é expressão da diversidade da natureza e da condição humana e não pode ser entendida como uma patologia (individual ou social), apesar de historicamente ter sido utilizada como sinônimo de desvio, anomalia ou anormalidade.

Os dados sugerem que o grupo de colegas da escola que conviviam com os participantes com DF apresentavam atitudes, valores e conteúdos cognitivos preconceituosos, com estereótipos e estigmas. Segundo Amaral (1992,1998) as atitudes preconceituosas, negativas, hostis e discriminatórios em relação aos outros membros do grupo são construídas a partir de julgamento prévio, anterior a qualquer conhecimento e experiência, caracterizandose como s relações de poder entre membros do grupo.

Neste sentido, no planejamento escolar faltou um trabalho conjunto de reflexão e conscientização com os atores sociais (professores, gestores, alunos, família, coordenadores) 
sobre diferenças, identidades e formas de exclusão social na pós-modernidade. A sensibilização sobre diversidade, inclusão e PCD auxilia a questionar valores, crenças, significados e atitudes adotados no sistema neoliberal (como o individualismo, a ideia de crescimento pela via da competição, o conceito de diferença e normalidade apoiado na ideia de corpo perfeito, etc.) que de forma geral os jovens e outros grupos absorvem sem questionar.

Os participantes Eurico e Carlos indicaram uma convivência positiva com colegas no ensino fundamental e médio. Nos depoimentos os temas mais recorrentes foram: colegas ótimos, boa relação e não ter problemas de convivência com colegas de escola. Os participantes associaram ao sentido dado, lembranças de imagens vividas na escola: brincar em grupo heterogêneo, jogar bola (mesmo na cadeira de rodas) e participar de trabalhos em equipe. Carlos narrou que algumas vezes colegas da escola brincavam na sua cadeira de rodas e achava divertido e todos riam juntos.

Entendemos que a interação entre pares é um aspecto importante no desenvolvimento e aprendizagem dos indivíduos, principalmente em uma prática escolar inclusiva. Colombina e Onrubia (2004) indicam processos interpsicológicos envolvidos na dinâmica interativa entre alunos e a aprendizagem escolar: sentimento de vinculação, busca de intersubjetividade, conflitos cognitivos e controvérsias conceituais, situações cooperativas, tutoria entre iguais, oferecimentos de explicações elaboradas, controle mútuo dos trabalhos e interdependência de objetivos.

\section{As atividades escolares e a prática docente}

Nesta categoria estão os depoimentos dos participantes sobre o ensino-aprendizagem e a prática pedagógica. Nesses relatos há um conteúdo cognitivo, emocional e sócio-afetivo, caracterizado por ideias, imagens atitudes, autopercepção, afeto, emoção, atitudes, valores e crenças. As temáticas mais presentes foram: dificuldades de realização das tarefas escolares acompanhado de anseios e insegurança, possibilidades de aprendizagem, compreensão das professoras quanto às dificuldades motoras finas, flexibilização/diferenciação da didática, da metodologia e da forma de avaliação e a falta dessa diversificação nas metodologias e forma de avaliar pelas professoras diante das dificuldades motoras.

Três participantes, Diana, Eurico, Carlos, narraram aspectos das atividades pedagógicas vivenciadas no ensino fundamental e médio. Os depoimentos estavam direcionados as subcategorias temáticas: dificuldades em tarefas que exigiam coordenação 
motora fina, liberação da professora nos exercícios de desenho geométrico, flexibilização na exigência da escrita e na forma de avaliar e tempo maior para realização das tarefas escolares. Os mesmos destacaram em seus relatos o quão era difícil realizar atividades que exigiam coordenação motora fina.

Para Carlos e Eurico o desenhar as formas geométricas nas aulas de matemática, era complicado, difícil e chato, e contavam com a compreensão das professoras que entendiam as dificuldades motoras. Assim também, eles tinham mais tempo que os outros alunos para executar a tarefa, não eram cobrados na ortografia, os procedimentos que exigiam coordenação motora fina eram flexibilizados pelos professores e tinham provas orais, sem afetar a qualidade do ensino-aprendizagem. Para os mesmos, os professores eram generosos, sempre consideravam a não perfeição no desenho das formas geométricas.

Diana tinha dificuldade na coordenação motora fina e na aquisição da leitura e escrita. Em seus depoimentos achava que tinha letra feia, aprendeu a ler sem copiar no quadro e percebia as professoras como pessoas rígidas, exigentes, sem paciência e com pouca compreensão das suas dificuldades motoras. As lembranças retratadas por Maria eram de professoras que chamavam sua atenção de forma grosseira por não saber escrever direito e não saber copiar da lousa, que diziam que não iriam copiar no seu caderno e que a letra dela era horrível, que deveria fazer um bom cabeçalho. O registro abaixo traduz o significado que Diana tinha sobre a aprendizagem e a prática docente:

A professora dizia: "Credo"! Que letra horrível! "Tamanha menina, não sabe escrever direito". O final do ano chegou e a professora disse que eu despertei muito tarde, por isso eu não pude passar de ano. Não acreditava que eu tinha capacidade de aprender. Nesse mesmo ano fiquei reprovada por 0,5 pontos, não lembro se foi português ou matemática, a professora não me deu 0,5. Apanhei da minha mãe. [...] com 10 anos, ainda no $1^{o}$ ano, (repeti quatro vezes), consegui passar. Na escola, reclamavam que minha letra era horrível, eu ouvia muito que minha letra era feia. [...] (Diana)

Diana revela que teve dificuldades em tarefas que exigiam a coordenação motora fina e na aquisição da leitura e escrita. A estudante traz aspectos da inclusão escolar, diferentes de Carlos e Eurico. Para os participantes houve compreensão das dificuldades inerentes à condição da deficiência e flexibilização curricular por parte dos professores (na identificação das necessidades/dificuldades do PCD, no método e na prática pedagógica, nos objetivos e 
nas avaliações), uma característica primordial da educação inclusiva e essas ações levaram ao êxito no processo de aprendizagem e escolarização.

No relato de Diana não se percebeu por parte dos professores a identificação das necessidades enquanto estudante PCD com flexibilização/diferenciação curricular nas práticas pedagógicas das escolas e dos docentes; assim também, observou-se intolerância e desrespeito dos professores. Verificou-se que a participante apresentou defasagem idade/série com várias reprovações ao longo de sua escolarização na educação básica.

Esses dados remetem a discussão sobre o currículo na perspectiva da diferenciação curricular. No nível pedagógico-curricular a diferenciação curricular é uma resposta para heterogeneidade de alunos, parte do pressuposto que os estudantes seguem o mesmo percurso, com a finalidade de atingir o sucesso educativo, mas que dependendo das características do aluno os caminhos são diferentes. Nesse sentido, pode ocorrer a alterações nos métodos e nos modos de organização do trabalho para o ensino-aprendizagem, nos objetivos, nos conteúdos, nas atividades e na avaliação do desempenho (Pacheco, 2008; Pletsch et al., 2017).

Outro ponto de destaque no depoimento de Diana foi o sentido dado à construção da leitura e escrita, quando a mesma afirma que não sabia como aprendeu a ler e escrever sem copiar da louça. Tal afirmativa revela um modo tradicional e mecânico de ver a construção da leitura e escrita: como um treino de habilidade motora e perceptiva da criança. A escrita e leitura é mais que uma aquisição percepto-motora, é uma construção intelectual da criança. Ferreiro e Teberosky (1991) afirmam que a aprendizagem da leitura e escrita é um ato ativo do sujeito cognoscente e não um ato mecânico. Nessa direção, para as autoras na aprendizagem de leitura e escrita, enquanto uma aquisição cognitiva, não se deve identificar leitura com decifrado, escrita com cópia de modelo, e nem identificar progressos na conceitualização com avanços no decifrado ou na exatidão da cópia.

Assim, as situações negativas vividas por Diana em sua escolarização são exemplos de práticas pedagógicas excludentes dentro de uma política e modelo educacional inclusivo, os dados não revelaram ações inclusivas exitosas. Questionamos se tivesse ocorrido sensibilização para o grupo identitário PCD e flexibilização/diferenciação curricular ao longo da escolarização será que a participante teria tantas retenções e reprovações?

\section{As dificuldades de acesso físico}

Nesta categoria estão agrupados os relatos sobre a acessibilidade física na escola. Eurico, Ivo, Carlos e Diana descrevem a acessibilidade da escola a partir dos seguintes 
atributos: acessibilidade pouca, ruim e complicada; necessidade de melhorias físicas na escola; falta de espaços adequados e de rampas ou mesmo, construídas fora do padrão, banheiro não adaptado, constrangimento e sentir-se incomodado por não conseguir acessar determinado espaço, ter dificuldade de acesso físico, muitas vezes precisar do outro para acessar espaços devido à falta de acessibilidade, com um sentimento de mal-estar.

A imagem do espaço girou em torno de suas vivências no ambiente escolar e da pouca infraestrutura, expressas nas situações: escola fora do nível da rua; rampas improvisadas para chegar à entrada da escola, com inclinação inadequada, muito alta e sem apoio e falta de rampas; por isso, não conseguiam sair sozinhos da sala; salas de aula e sala de vídeo no andar superior e escola sem elevador; banheiros e laboratórios não adequados. Por essas condições não acessíveis da escola, relataram que muitas vezes precisavam de ajuda (como por exemplo, ser carregado no colo) e isso provocava mal-estar e um sentimento de se perceber inferior, uma marca. Vejamos os depoimentos:

Na escola, a superfície era alta incompatível com o nível da rua, então eles improvisavam qualquer coisa para servir de rampa, mas sem cálculo, sem apoio de forma grosseira e por esse motivo, sempre precisava de ajuda, para não sofrer uma queda, era um constrangimento.

A escola não tinha elevador e a escola só climatizou o andar superior. Então minha turma a teve que permanecer no andar inferior sem climatização por minha causa e colegas me constrangiam por não usufruirmos da climatização, ai minha família teve que interferir junto à direção da escola. Assim também a salas de vídeo eram todas no andar superior e, para subir, sempre precisava ser carregado no colo, o que me marcou de forma significante.

Portanto, os participantes expressam o pouco preparo das escolas para atender as necessidades de alunos com deficiência física no que se refere a prover a acessibilidade e a estimular as mudanças atitudinais de toda a comunidade escolar.

Apesar de documentos legais e políticos, e.g.: o Decreto n.5.296 (2004) e o Estatuto da Pessoa com Deficiência (Lei n. 13.146, 2015), não se percebeu nas RS dos participantes que as escolas obedeciam à legislação vigente para garantir o acesso físico aos estudantes PCD.

Concordamos com autores como Duarte \& Cohen (2004) e Manzini \& Correa (2008) ao afirmarem que a acessibilidade, descrita, como medidas técnico-sociais devem favorecer a 
todos, inclusive aos PCD facilitando a inclusão social. Essa tem um papel importante para diminuir as desigualdades e estabelecer um ambiente de acolhimento, conforto e facilidade.

Portanto, historicamente as escolas não se prepararam para ter ambientes acessíveis o que provoca situações de desigualdade, dificuldades na aprendizagem, situações de constrangimento e exclusão social aos estudantes PCD.

As três categorias temáticas, a saber: as relações afetivas: professores-estudante com DF e estudantes não deficientes-estudante com DF, as atividades escolares e a prática docente, e as dificuldades de acesso físico, possibilitaram perceber aspectos da inclusão escolar dos universitários com DF. Deste modo, se buscou interpretar o significado dado as situações vividas construídas no cotidiano escolar: as relações com os pares (estudantes) e professores, as atitudes e as dificuldades de interações, o acolhimento de alguns professores e a ausência de outros, os preconceitos e agressões sofridos pelos pares; as atividades escolares e os processos de ensino-aprendizagem, os sentimentos vivenciados, as dificuldades, os valores e as ideias produzidas e a pouca acessibilidade física nos espaços escolares com os transtornos e o sentimento de mal-estar.

\section{As relações afetivas entre professores e estudante não deficientes}

Esta categoria agrega depoimentos dos estudantes com DF sobre os tipos de relações vivenciadas com os professores e com estudantes não deficientes. Estes relatos foram apoiadas tanto no aspecto sócio-afetivo, quanto no cognitivo, associando sentidos e lembranças de atitudes, ações, vocalizações, da figura do professor e dos estudantes não deficientes.

Os estudantes expressaram o significado dado à relação professor-aluno no qual o afeto (positivo e negativo, a compreensão, a linguagem e o pensamento estavam engendrados). Carlos, Eurico e Ivo indicaram em suas narrativas situações de relação positiva ou afetividade prazerosa com professores no ensino fundamental e médio. Para os participantes os sentidos à figura e atitudes dos professores foram de acolhimento, paciência, compreensão, justiça, generosidade, atendimento as necessidades da deficiência e defesa contra o bullying.

Diana em seus relatos sobre a relação professor-aluno expressou tanto episódios de relações positivas, quanto negativas, com maior destaque para depoimentos de afetividade negativa; nas falas sobre o relacionamento estavam presentes principalmente atitudes de preconceito, indiferença e agressividade das professoras. Essas atitudes ajudaram a produzir 
uma autopercepção negativa. A participante também narrou situações de atitudes acolhedoras e compreensivas de algumas professoras, segundo a mesma, foram poucos anos de convivência positiva e esse tipo de convivência ajudou a melhorar sua autoestima e a percepção de si.

Além dos significados, os participantes trouxeram imagens, lembranças que guardam nas memórias. Carlos, Eurico, e Ivo recordaram imagens da ação docente: cenas da professora defendendo contra alunos que os tratavam com agressividade, episódios de respeito a todos os alunos na sala de aula, sem fazer diferença entre estudantes; momentos de ajuda aos participantes em decorrência da dificuldade motora nos membros superiores, inerente à deficiência física. Outra cena lembrada pelos estudantes foi a flexibilização na forma de avaliação, onde em muitos momentos eles faziam prova oral e não era exigido o desenho geométrico nas aulas e provas de matemática.

Diana lembrou em seu relato, principalmente situações negativas, as memórias foram de imagens de afetividade negativa com algumas professoras. Ao compara-las negativamente com outros alunos e ignorarem suas dificuldades motoras e de aprendizagem. Essas ações das professoras geravam em Diana um sentimento de insegurança, de se sentir incapaz e desmotivada.

Vejamos algumas narrativas dos estudantes com DF sobre a relação professor-aluno:

[...] Sempre foram ótimos comigo. Lá os professores e colegas eram ótimos se tinha um problema, os professores tentavam resolver, como por exemplo, o atraso na impressão da prova (Eurico).

Ficava chateada quando acertava alguma coisa que ninguém acertava e a professora se admirava e dizia: "Até a Maria que tem problemas conseguiu acertar essa questão e vocês não". Com esse comentário ela demonstrava que me achava uma pessoa incapaz de aprender [...]. Posso recordar acontecimentos marcantes para mim, como a fala de uma professora que dizia: "tu nunca sai da $4^{a}$ série, assim, não chegarás a lugar algum" [...]. (Diana).

Os dados evidenciam maior quantidade de afetividade positiva do que negativa na relação professor-aluno expressos nas temáticas: auxílio ao aluno, compreensão e respeito o que impactou na sensação de pertencimento a escola, na autoestima do aluno e na capacidade de aprender. Uma participante expressou e retratou situações negativas na convivência com professores. Portanto, na dinâmica interacional destacaram-se: a afetividade prazerosa ou 
positiva com emoções, as atitudes, afeto, a compreensão e a consciência; assim também, em menor frequência houve relatos de descaso, de indiferença e de agressividade no contato de professores com estudantes com DF.

Miras (2004) afirma que as reações emocionais do professor e a informação afetiva que o aluno recebe do professor são importantes para compreender e regular as próprias relações. Em algumas situações os estudantes aprendem a ocultar as emoções negativas para permanecer no contexto escolar, e quando há uma alta intensidade de emoção negativa, possivelmente os estudantes se concentram mais no aspecto afetivo-emocional do que na dimensão cognitiva do ensino-aprendizagem. A autora ressalta também, que afeto e aprendizagem estão intrinsicamente relacionados, a forma como o professor reage emocionalmente diante do sucesso ou fracasso do aluno influencia a autoestima e a expectativa de sucesso do mesmo.

Na mesma linha de argumentação, Baker (2006), destaca que a qualidade da relação professor-aluno influencia no ensino-aprendizagem, principalmente na adaptação escolar, na autoconfiança e na motivação escolar dos estudantes.

Sobre a relação entre aluno com DF e alunos sem deficiência, os participantes relataram maior prevalência de interações negativas. Diana e Ivo trouxeram depoimentos da qualidade das interações com os colegas da escola; os temas mais recorrentes foram: afetividade e emoções negativas, deficiência, diferença, discriminação, preconceito, valores, agressividade física e verbal, bullying falta de respeito. Associadas a esses significados os participantes relembram situações vividas; essas imagens foram retratadas em cenas em que os colegas não deficientes zombavam do corpo deficiente, apelidavam de aleijado (a), escutavam piadas sobre sua deficiência e brincarem com suas cadeiras de rodas sem autorização dos mesmos e em algumas situações eles caiam da cadeira de rodas. Essas experiências vividas provocavam tristeza, mal-estar, vontade de abandonar a escola, constrangimento, sensação de não se sentir pertencente ao grupo, não ter amigos e dificuldade de se relacionar. O depoimento de Ivo mostra os sentidos e imagens sobre a relação com os colegas da escola, interações estas marcadas pelo preconceito, agressão e falta de consciência.

Não havia muito respeito dos colegas; na $6^{a}$ serie, na aula de educação física, um aluno mexeu comigo, e falou mal minha família, ai dei uma cotovelada nele, e com a cotovelada que dei nele, ele era gordinho, ele teve falta de ar, foi nós dois para diretoria, não mexeu mais comigo. Na $8^{a}$ serie, alguns alunos bagunceiros, pegavam minha cadeira e rodavam e 
Research, Society and Development, v. 9, n. 10, e1569108162, 2020

(CC BY 4.0) | ISSN 2525-3409 | DOI: http://dx.doi.org/10.33448/rsd-v9i10.8162

rodavam ou corriam com ela em linha reta. Eu ficava triste; ai, eu não quis mais estudar, depois passou.

As informações dos participantes sobre a afetividade negativa na relação aluno com DF e alunos sem deficiência remete à discussão sobre a representação da pessoa com deficiência na relação com o conceito de normalidade e preconceito.

Historicamente, a pessoa com deficiência foi vista a partir de um modelo médico ou do déficit que se fundamentou na ideia de que a deficiência era uma condição individual a partir de um parâmetro de normalidade, nesse sentido. A deficiência foi associada à ideia de desvio de curva média, de anormalidade, de diferença, tratando-se de um mecanismo de segregação a uma parte da população. Em contrapartida, a esse modelo o paradigma social surgido na década 60 do século passado, compreende a deficiência como uma construção social, a partir da relação do indivíduo e as condições da sociedade (históricas, materiais e políticas) que discriminam, diferenciam e excluem.

Portanto, é sugestivo pensar que os colegas da escola que agrediram e desrespeitaram os estudantes Ivo e Diana tiveram atitudes preconceituosas e discriminatórias a partir de uma visão da deficiência/diferença enquanto anormalidade e inferioridade. Essa categoria desvela a necessidade de se compreender o sentido das atitudes preconceituosas a partir da visão de deficiência e diferença.

Segundo Guareschi (1992) os critérios de "normalidade" são rotativos, sofrem alguma alternância e implica relações de poder. Esses significados são alterados conforme o contexto político, cultural e histórico da sociedade afirma que. Nessa mesma linha de argumentação, Amaral (1998) afirma que a diferença significativa (a partir de aspectos como peso, cor, cognição, opção sexual, religião, gênero, envelhecimento e deficiência entre outros) foi considerada desvio ou anormalidade. Para a autora a deficiência é expressão da diversidade da natureza e da condição humana e não pode ser entendida como uma patologia (individual ou social), apesar de historicamente ter sido utilizada como sinônimo de desvio, anomalia ou anormalidade.

Os dados sugerem que o grupo de colegas da escola que conviviam com os participantes com DF apresentavam atitudes, valores e conteúdos cognitivos preconceituosos, com estereótipos e estigmas. Segundo Amaral (1992,1998) as atitudes preconceituosas, negativas, hostis e discriminatórios em relação aos outros membros do grupo são construídas a partir de julgamento prévio, anterior a qualquer conhecimento e à experiência e as relações de poder entre membros do grupo. 
Neste sentido, no planejamento escolar faltou um trabalho conjunto de reflexão e conscientização com os atores sociais (professores, gestores, alunos, família, coordenadores) sobre diferenças, identidades e formas de exclusão social na pós-modernidade. A sensibilização sobre diversidade, inclusão e PCD auxilia a questionar valores, crenças, significados e atitudes adotados no sistema neoliberal (como o individualismo, a ideia de crescimento pela via da competição, o conceito de diferença e normalidade apoiado na ideia de corpo perfeito, etc.) que de forma geral os jovens e outros grupos absorvem sem questionar.

Os participantes Eurico e Carlos indicaram uma convivência positiva com colegas no ensino fundamental e médio. Nos depoimentos os temas mais recorrentes foram: colegas ótimos, boa relação e não ter problemas de convivência com colegas de escola. Os participantes associaram ao sentido dado, lembranças de imagens vividas na escola: brincar em grupo heterogêneo, jogar bola (mesmo na cadeira de rodas) e participar de trabalhos em equipe. Carlos narrou que algumas vezes colegas da escola brincavam na sua cadeira de rodas e achava divertido e todos riam juntos.

Entendemos que a interação entre pares é um aspecto importante no desenvolvimento e aprendizagem dos indivíduos, principalmente em uma prática escolar inclusiva. Colombina e Onrubia (2004) indicam processos interpsicológicos envolvidos na dinâmica interativa entre alunos na relação com a aprendizagem escolar: sentimento de vinculação, busca de intersubjetividade, conflitos cognitivos e controvérsias conceituais, situações cooperativas, tutoria entre iguais, oferecimentos de explicações elaboradas, controle mútuo dos trabalhos e interdependência de objetivos.

\section{As atividades escolares e a prática docente}

Nesta categoria estão os depoimentos dos participantes sobre o ensino-aprendizagem e a prática pedagógica. Nesses relatos há um conteúdo cognitivo, emocional e sócio-afetivo, caracterizado por ideias, imagens atitudes, autopercepção, afeto, emoção, atitudes, valores e crenças. As temáticas mais presentes foram: dificuldades de realização das tarefas escolares acompanhado de anseios e insegurança, possibilidades de aprendizagem, compreensão das professoras quanto às dificuldades motoras finas, flexibilização/diferenciação da didática, da metodologia e da forma de avaliação e a falta dessa diversificação nas metodologias e forma de avaliar pelas professoras diante das dificuldades motoras. 
Três participantes, Diana, Eurico, Carlos, narraram aspectos das atividades pedagógicas vivenciadas no ensino fundamental e médio. Os depoimentos estavam direcionados as subcategorias temáticas: dificuldades em tarefas que exigiam coordenação motora fina, liberação da professora nos exercícios de desenho geométrico, flexibilização na exigência da escrita e na forma de avaliar e tempo maior para realização das tarefas escolares. Os mesmos destacaram em seus relatos o quão era difícil realizar atividades que exigiam coordenação motora fina.

Para Carlos e Eurico o desenhar as formas geométricas nas aulas de matemática, era complicado, difícil e chato, e contavam com a compreensão das professoras que entendiam as dificuldades motoras. Assim também, eles tinham mais tempo que os outros alunos para executar a tarefa, não eram cobrados na ortografia, os procedimentos que exigiam coordenação motora fina eram flexibilizados pelos professores e tinham provas orais, sem afetar a qualidade do ensino-aprendizagem. Para os mesmos os professores eram generosos, sempre consideravam a não perfeição no desenho das formas geométricas.

Diana tinha dificuldade na coordenação motora fina e na aquisição da leitura e escrita. Em seus depoimentos achava que tinha letra feia, aprendeu a ler sem copiar no quadro e percebia as professoras como pessoas rígidas, exigentes, sem paciência e com pouca compreensão das suas dificuldades motoras. As lembranças retratadas por Maria eram de professoras que chamavam sua atenção de forma grosseira por não saber escrever direito e não saber copiar da lousa, que diziam que não iriam copiar no seu caderno e que a letra dela era horrível; que deveria fazer um bom cabeçalho. O registro abaixo traduz o significado e imagem que Diana tinha sobre aprendizagem e prática docente:

A professora dizia: "Credo"! Que letra horrivel! "Tamanha menina, não sabe escrever direito". O final do ano chegou e a professora disse que eu despertei muito tarde, por isso eu não pude passar de ano. Não acreditava que eu tinha capacidade de aprender. Nesse mesmo ano fiquei reprovada por 0,5 pontos, não lembro se foi português ou matemática, a professora não me deu 0,5. Apanhei da minha mãe. [...] com 10 anos, ainda no $1^{\circ}$ ano, (repeti quatro vezes), consegui passar. Na escola, reclamavam que minha letra era horrível, eu ouvia muito que minha letra era feia. [...] (Diana)

Diana revela que teve dificuldades em tarefas que exigiam a coordenação motora fina e na aquisição da leitura e escrita. A estudante traz aspectos da inclusão escolar, diferentes de Carlos e Eurico. Para os participantes houve compreensão das dificuldades inerentes à 
condição da deficiência e flexibilização curricular por parte dos professores (na identificação das necessidades/dificuldades do PCD, no método e na prática pedagógica, nos objetivos e nas avaliações), uma característica primordial da educação inclusiva e essas ações levaram ao êxito no processo de aprendizagem e escolarização.

No relato de Diana não se percebeu por parte dos professores a identificação das necessidades enquanto estudante PCD e flexibilização/diferenciação curricular nas práticas pedagógicas das escolas e dos docentes; assim também, observou-se intolerância e desrespeito dos professores. Verificou-se que a participante apresentou defasagem idade/série com várias reprovações ao longo de sua escolarização na educação básica.

Esses dados remetem a discussão sobre o currículo na perspectiva da diferenciação curricular. No nível pedagógico-curricular a diferenciação curricular é uma resposta para heterogeneidade de alunos, parte do pressuposto que os estudantes seguem o mesmo percurso, com a finalidade de atingir o sucesso educativo, mas que dependendo das características do aluno os caminhos são diferentes, nesse sentido pode ocorrer a alterações nos métodos e maneiras de organização do trabalho no ensino-aprendizagem; nos objetivos, nos conteúdos, nas atividades e na avaliação do desempenho (Pacheco, 2008; Pletsch et al., 2017).

Outro ponto de destaque no depoimento de Diana foi o sentido dado à construção da leitura e escrita, quando a mesma afirma que não sabia como aprendeu a ler e escrever sem copiar da louça. Tal afirmativa revela um modo tradicional e mecânico de ver a construção da leitura e escrita: como um treino de habilidade motora e perceptiva da criança. A escrita e leitura são mais que uma aquisição percepto-motora, é uma construção intelectual da criança. Ferreiro e Teberosky (1991) afirmam que a aprendizagem da leitura e escrita é um ato ativo do sujeito cognoscente e não um ato mecânico. Nesse sentido, para as autoras na aprendizagem de leitura e escrita (uma aquisição cognitiva) não se deve identificar leitura com decifrado, escrita com cópia de modelo, e nem identificar progressos na conceitualização com avanços no decifrado ou na exatidão da cópia.

Assim, as situações negativas vividas por Diana em sua escolarização são exemplos de práticas pedagógicas excludentes dentro de uma política e modelo educacional inclusivo, os dados não revelaram ações inclusivas exitosas. Questionamos se tivesse ocorrido sensibilização para o grupo identitário PCD e flexibilização/diferenciação curricular ao longo da escolarização será que ela teria tantas retenções e reprovações? 


\section{As dificuldades de acesso físico}

Nesta categoria estão agrupados os relatos sobre a acessibilidade física na escola. Eurico, Ivo, Carlos e Diana descrevem a acessibilidade da escola a partir dos seguintes atributos: acessibilidade pouca, ruim e complicada; necessidade de melhorias físicas na escola; falta de espaços adequados e de rampas ou mesmo, construídas fora do padrão, banheiro não adaptado, constrangimento e sentir-se incomodado por não conseguir acessar determinado espaço, ter dificuldade de acesso físico, muitas vezes precisar do outro para acessar espaços devido à falta de acessibilidade, com um sentimento de mal-estar.

A percepção sobre o espaço físico girou em torno das vivências no ambiente escolar: a pouca infraestrutura, escola fora do nível da rua, rampas improvisadas para chegar à entrada da escola, com inclinação inadequada, muito alta e sem apoio e falta de rampas, salas de aula e sala de vídeo no andar superior e escola sem elevador, banheiros e laboratórios não adequados. Essa falta de acessibilidade impedia de ter autonomia, de sair sozinhos da sala e da escola, em muitas situações precisavam ser carregados no colo e isso provocava mal-estar, e um sentimento de inferioridade. Vejamos os depoimentos:

$\mathrm{Na}$ escola, a superfície era alta incompatível com o nível da rua, então eles improvisavam qualquer coisa para servir de rampa, mas sem cálculo, sem apoio de forma grosseira e por esse motivo, sempre precisava de ajuda, para não sofrer uma queda, era um constrangimento.

A escola não tinha elevador e a escola só climatizou o andar superior. Então minha turma a teve que permanecer no andar inferior sem climatização por minha causa e colegas me constrangiam por não usufruirmos da climatização, ai minha família teve que interferir junto à direção da escola. Assim também a salas de vídeo eram todas no andar superior e, para subir, sempre precisava ser carregado no colo, o que me marcou de forma significante.

Portanto, os participantes expressam o pouco preparo das escolas para atender as necessidades de alunos com deficiência física no que se refere a prover a acessibilidade e a estimular as mudanças atitudinais de toda a comunidade escolar. 
Apesar de documentos legais e políticos, e.g.: o Decreto n.5.296 (2004) e o Estatuto da Pessoa com Deficiência (Lei n. 13.146, 2015), não se percebeu nas RS dos participantes que as escolas obedeciam à legislação vigente para garantir o acesso físico aos estudantes PCD.

Concordamos com autores como Duarte \& Cohen (2004) e Manzini \& Correa (2008) ao afirmarem que a acessibilidade, descrita, como medidas técnico-sociais devem favorecer a todos, inclusive aos PCD facilitando a inclusão social. Essa tem um papel importante para diminuir as desigualdades e estabelecer um ambiente de acolhimento, conforto e facilidade.

Portanto, historicamente as escolas não se prepararam para ter ambientes acessíveis o que provoca situações de desigualdade, dificuldades na aprendizagem, situações de constrangimento e exclusão social aos estudantes PCD.

\section{Considerações Finais}

Tomando como base o objetivo do artigo que foi compreender a percepção dos estudantes universitários com DF sobre aspectos da inclusão escolar, a análise foi realizada a partir das categorias temáticas: as relações afetivas entre professores e estudante não deficientes; as atividades escolares e a prática docente e as dificuldades de acesso físico; o que permitiu concluir que a inclusão escolar enquanto processo, apresenta alguns avanços, dificuldades e desafios, principalmente na dimensão relacional (entre alunos não deficientes e alunos deficientes) e na acessibilidade física.

Os resultados da pesquisa revelaram que as relações afetivas professor- alunos com DF e alunos não deficientes- alunos com DF se apoiavam tanto em dimensões sócio-afetivo, quanto cognitiva. O significado dado à relação professor-aluno para três participantes foi de afeto positivo ou prazeroso em que predominava um conjunto de atitudes positivas do professor como: compreensão, consciência, acolhimento, respeito, ajuda e apoio no momento que precisavam; exceto para uma participante que relatou maior prevalência de relações negativas com professores, o que segundo a mesma afetou sua autoestima e seu aprendizado.

$\mathrm{Na}$ dimensão relações entre estudantes com DF e estudantes não deficientes houve maior prevalência de narrativas de situações negativas, onde foi observado o preconceito, a agressividade e situações de desrespeito por parte de estudantes não deficientes. Um participante relatou situações de afetividade positiva. Nesse aspecto é possível supor que o modelo de educação inclusiva é um desafio para as escolas, e precisa ser trabalhada no cotidiano escolar. Uma das sugestões para tratar essa dimensão seria incluir no planejamento pedagógico da escola, eventos com o objetivo de trabalhar a consciência crítica do coletivo 
escolar para o surgimento de novos discursos e práticas, principalmente dos estudantes não deficientes. Esses eventos poderiam ser rodas de conversa, debates, seminários e oficinas para se trabalhar de forma criativa e reflexiva, temáticas como: diferenças, normalidade e anormalidade, identidades e deficiência a partir de abordagens crítica e pós-crítica da educação e psicologia.

$\mathrm{Na}$ categoria atividades escolares e prática docente, os dados apontaram dificuldades (acompanhados de anseios e inseguranças) na realização das tarefas escolares que precisavam a coordenação motora fina, como em desenhos geométricos ou na escrita de textos. Três participantes comentaram sobre as práticas docentes, como a compreensão das professoras quanto às dificuldades supracitadas e flexibilização/diferenciação na didática, na metodologia e na forma de avaliar, o que para eles impactou positivamente na aprendizagem.

Uma participante em seu depoimento enfatizou com mais frequência insatisfação quando a atuação de professores, relacionando-a ao baixo desempenho em sua aprendizagem e diversas reprovações. Ao mencionar sobre as práticas docentes, destacou a pouca disponibilidade de professores em entender suas dificuldades (principalmente referente à coordenação motora fina), a não flexibilização de metodologias e formas de avaliação. Citou a obrigatoriedade de realizar tarefas escolares, tais quais os estudantes não deficientes, exigência no formato da escrita ao invés de compreensão da leitura e da escrita. Essas práticas pedagógicas influenciaram negativamente em sua aprendizagem e autoestima, o que fez ter um rendimento escolar baixo, ficar reprovado por várias vezes e ter distorção idade/serie.

A participante relatou também, algumas situações (em menor frequência) em que professoras compreenderam as limitações da deficiência física e proporcionaram práticas pedagógicas inclusivas, com acolhimento, métodos e avaliação diferenciada. Essas ações impactaram positivamente na aprendizagem e no modo de se perceber, gerando uma autoestima positiva e aprovação no rendimento escolar.

A prática docente é uma das dimensões importante dentro de um modelo de educação inclusiva. Nessa perspectiva, o professor exerce não só um papel de técnico, de construtor de conhecimento científico, de manuseador de técnicas e de métodos para a regência de classe; mas também, deve possuir um conjunto de saberes crítico reflexivo como, por exemplo, sobre sociedade, cultura, educação, diferenças, diversidade, inclusão. Esses saberes auxiliariam a trabalhar na perspectiva da diversidade e da inclusão, na construção das múltiplas identidades no contexto da escola e no desenvolvimento de cidadania dos estudantes com DF; consequentemente conduzindo o ensino para uma aprendizagem eficaz na perspectiva da heterogeneidade e da diversidade. Nessa direção, é preciso pensar em práticas docentes que 
levem ao sucesso na aprendizagem, com atuação crítica e reflexiva, que colabore para a escolarização dos estudantes com DF, para que não ocorram práticas excludentes, que favoreçam o fracasso escolar.

Portanto, um caminho para a ocorrência de práticas docentes exitosas para educação inclusiva seria a formação do professor em serviço. Sugerimos não somente trabalhar a diferenciação curricular na perspectiva técnica (métodos, recursos e modos de avaliar, atividades) em turmas inclusivas com PCD, é preciso questionar e refletir criticamente sobre questões como sociedade, diversidade e diferenças inclusão, identidades, ideologias, crenças, valores e significados. Isso posto, se as instituições não valorizarem e oferecerem esse tipo de formação, as práticas inclusivas e consequentemente o ensino-aprendizagem fica comprometido.

Outro ponto observado nas narrativas refere-se às práticas pedagógicas em escolas públicas e privadas. Três participantes estudaram a educação básica em escola privada e essas escolas ofereceram práticas inclusivas. A participante que estudou em escola pública relatou mais práticas excludentes. Os dados não oferecem possibilidades de análises conclusivas sobre a relação educação inclusiva e escolas públicas e privadas; desse modo, nessa temática deixo o debate em aberto, com possibilidades para novas pesquisas.

Destacam-se também nas narrativas as dificuldades de acessibilidade física no ambiente escolar; central na discussão sobre o modelo de educação inclusiva. Apesar de um conjunto de aparatos legais e políticos que regulamentam a acessibilidade física nos diversos ambientes, as narrativas dos sujeitos vêm indicar que essas normativas não são cumpridas nas escolas, caracterizando como uma barreira para a inclusão. Portanto, não basta atuar somente nos aspectos pedagógicos e curriculares, se faz necessário criar condições concretas de acesso ao espaço físico, para que os estudantes sintam-se incluídos de fato, com a sensação de pertencimento, tenham o direito de ir e vir e sejam respeitados enquanto cidadãos a partir de suas características.

Em suma, essas foram algumas dimensões levantadas a respeito da inclusão escolar no ensino médio e fundamental de pessoas com DF. Vale lembrar que a inclusão educacional está relacionada a um conjunto de fatores macrossocial que envolve entre outros, o regime de governo, o sistema socioeconômico e políticas públicas eficazes, principalmente na área da educação, saúde e assistência social o que influencia os diversos aspectos das dinâmicas educativas no cotidiano das escolas.

Esperamos que a pesquisa proporcione reflexões sobre a política educacional inclusiva e as práticas nas escolas, levando em consideração novas perspectivas e a possibilidade de 
práticas exitosas para os alunos com DF, bem como, oferecer subsídios de debates para as instituições públicas e privadas na área educacional.

\section{Referências}

Amaral, L. A. (1992). Espelho convexo: o corpo desviante no imaginário coletivo, pela voz da literatura infanto-juvenil. (Tese de doutorado). Universidade de São Paulo, São Paulo, SP.

Amaral, L. A. (1998). Sobre crocodilos e avestruzes: falando de diferenças físicas e sua superação. In J. G. Aquino (org.), Diferenças e preconceitos na escola: alternativas teóricas e práticas, 11-30. São Paulo: Summus.

Baker, J. A. (2006). Contributions of teacher-child relationships to positive school adjustment during elementary school. Journal of School Psychology, 44 (3), 211229. doi.org/10.1016/j.jsp.2006.02.002

Bardin, L. (2011). Análise de conteúdo. (3a ed). Lisboa: Edições 70.

Baú, M. A. (2015). Avaliação da acessibilidade no ensino superior. (Dissertação de mestrado). Universidade Estadual Paulista, UNESP, Marília, SP.

Colomina, R., \& Onrubia, J. (2004). Interação educacional e aprendizagem escolar: a interação entre alunos. In C. Coll; J. Palácios \& A. Marchesi (orgs.), Desenvolvimento Psicológico e Educação (pp. 280-293). Porto Alegre: Artmed.

Decreto n. ${ }^{\circ} 5.296$ de 02 de dezembro de 2004. Diário Oficial da União de 3.12.2004. Brasília: Ministério da Educação. Secretaria de Educação Especial. Recuperado: 10 jan.2020. Disponível: http://portal.mec.gov.br

Ferreiro, E., \& Teberosky, A. (1991). Psicogênese da língua escrita. (4ª ed.). Porto Alegre: Artes Médicas. 
Glat, R. (2011). Educação inclusiva para alunos com necessidades especiais: processos educacionais e diversidade. In M. D. Longuini (Org.), O uno e o diverso na educação (pp.7591). Uberlândia: EDUFU.

Gonçalves, H. de A. (2005). Manual de Projetos de Pesquisa Científica. São Paulo: Avercamp.

Guareschi, P. A. (1992). A categoria "Excluídos". Psicologia: Ciência e Profissão.[online], 12(3-4), 4-11. doi.org/10.1590/S1414-98931992000300002

Lei $n^{o}$ 13.146, de 06 de julho de 2015. Institui a Lei Brasileira de Inclusão da Pessoa com Deficiência (Estatuto da Pessoa com Deficiência). Recuperado de http://www.planalto.gov.br/ccivil_03/_ato2015-2018/2015/lei/113146.htm

Miras, M. (2004). Afetos, emoções, atribuições e expectativas: o sentido da aprendizagem escolar. In C. Coll, A. Marchesi, \& J. Palácios (Orgs.), Desenvolvimento psicológico e educação (pp. 210-212). Porto Alegre: Artmed.

Pacheco, J. A. (2008). Notas sobre diversificação/ diferenciação curricular em Portugal. InterMeio, 14(28), 178-187. Recuperado de http://200.129.202.50/index.php/in tm/article/view/2498

Pletsch, M. D. (2011). A dialética da inclusão x exclusão nas políticas educacionais para pessoas com deficiência: um balanço do governo Lula. Revista Teias, 12(24), 39-55.

Recuperado de https://www.e-publicacoes.uerj.br/index.php/revistateias /article/view/24189/17168

Pletsch, M. D., Lima, M. F. C. (2014). A inclusão escolar de alunos com autismo: um olhar sobre a mediação pedagógica. In Anais Seminário Internacional de Inclusão Escolar. Rio de Janeiro, Brasil: Universidade do Estado do Rio de Janeiro.

Pletsch, M. D., Souza, F. F. de, \& Orleans, L. F. (2017). A diferenciação curricular e o desenho universal na aprendizagem como princípios para a inclusão escolar. Educação $e$ Cultura Contemporânea, 14 (35), 264-281. doi:10.5935/2238-1279.20170014 
Política Nacional de Educação Especial na Perspectiva da Educação Inclusiva Brasil PNEEI. Ministério da Educação. Secretaria de Educação Especial (2008). Brasília: MEC/SEESP. Recuperado: 12 fev.2020. Recuperado de http://portal.mec.gov.br

Santos filho, J. C., \& Gamboa, S. S. (2009). Pesquisa Educacional: quantidade-qualidade. (7.ed.). São Paulo: Cortez.

Sousa, N. M., \& Nascimento, D. (2018). A inclusão escolar e o aluno com síndrome de Down: as adaptações curriculares e a avaliação da aprendizagem. Educação \& Formação, 3(3), 121-140. doi.org/10.25053/redufor.v3i9.859.

\section{Porcentagem de contribuição de cada autor no manuscrito}

Neide Maria Fernandes Rodrigues de Sousa - 80\%

Ivany Pinto Nascimento - 20\% 